\title{
Erratum
}

\section{Integration of practical supplemental measurements into bridge condition visual inspection grading}

\author{
Nefize Shaban ${ }^{\mathrm{a}}$, Ozgur Avsar ${ }^{\mathrm{b}}$ and Alp Caner ${ }^{\mathrm{c}}$ \\ ${ }^{a}$ Northern Cyprus Middle East Technical University, Department of Civil Engineering, Mersin, Turkey \\ ${ }^{\mathrm{b}}$ Eskisehir Technical University, Department of Civil Engineering, Eskisehir, Turkey \\ ${ }^{\mathrm{c}}$ Middle East Technical University, Department of Civil Engineering, Ankara, Turkey
}

[Journal of Bridge Structures, 16 (4) (2020), 139-153 DOI 10.3233/BRS-200179]

https://content.iospress.com/articles/bridge-structures/brs200179

In the print file, the name of the first author, Nefize Shaban, was misspelled as Nefize Shabana. This has been corrected in the online version of the article (https://doi.org/10.3233/BRS-200179). 